\title{
Tackling in Physical Education Rugby: An Unnecessary Risk?
}

\section{The Call to Ban Tackling in Physical Education Rugby}

Since 2016, we have been strong advocates for the removal of tackling from rugby (League and Union) played in school physical education in the United Kingdom [1]. This is because (a) tackling is the leading cause of injury in rugby, (b) rugby has a level of risk that is higher than non-contact sports, (c) there is no requirement or need for tackling as part of the school physical education curriculum, and (d) many children are compelled to participate in contact rugby [2]. In response to this call, the Chief Medical Officers and the Physical Activity Expert Group commented: 'The Committee reject the call to ban tackling, as they do not feel rugby participation poses an unacceptable risk of harm' [3]. Yet, the notion of risk (un) acceptability is a construct that needs further discussion, which we will start here [4].

\section{Risk Acceptance}

What makes a risk acceptable or not is somewhat contextually subjective [4]. Molcho and Pickett, however, have attempted to define some boundaries of unacceptable risk for children. Specifically, they suggest that: 'the following are deemed non-acceptable: (1) intentional injuries; (2) severe or disabling injuries; (3) injuries while involved in unhealthy, unnecessary or abnormally risky behaviours; and (4) injuries that occurred while ignoring known preventative measures' [5]. As a result, each of these criteria will be explored in turn.

\section{Intentional Injuries}

Rugby Union and Rugby League are contact sports. While the objective for attacking players is to evade their opposition and invade their territory, defenders are seeking to hinder this progress through contact. Tackling, therefore, is a structural element of play while also being the primary cause of injuries. Other than foul play however - which is unfortunate but commonplace in all sports - the vast majority of injuries in rugby are likely to be unintentional.

\section{Severe or Disabling Injuries}

Concussion is a common injury in contact rugby [6]. However, the evidence on the specific mechanisms and protective factors surrounding concussions, as well as the many related degenerative brain disorders (e.g., Chronic Traumatic Encephalopathy) associated with concussion, is still developing [7]. Yet, we do recognise that long-term neurodegenerative disease is one of the possible outcomes of concussion. Indeed, while the extent and exact causal mechanisms of concussion are not fully known, the trajectory of evidence is compelling, with the consequences potentially severe or disabling. In addition to concussion, there are also other forms of severe injuries in youth rugby; e.g., catastrophic spine / neck injuries $[8,9]$.

\section{Unnecessary Risk}

The physical education curriculum in the United Kingdom does not make any particular sport mandatory, meaning curriculum decisions are the responsibility of individual schools. However, many schools do opt to make rugby, inclusive of tackling, compulsory for their pupils [2]. Consequently, tackling is not a voluntary activity, meaning the acceptable levels of risk are lower than in the community (or voluntary) context [10]. Yet, if there is no essential obligation for children to tackle to meet the requirements of physical education, the risks 
associated with tackling are unnecessary. Thus, unless there is evidence of a unique benefit associated with tackling that is unachievable through safer activities, the arguments to maintain tackling are sport-focused rather than child-centred.

\section{Preventative Measures}

Some have suggested that coach/teacher education, such as correct tackle technique development, is the solution to injury and concussion concerns in physical education rugby. Yet, despite initial evidence from the professional and elite youth game that tackle technique has the potential to reduce injury risk [11 - 13], evidence of the relationship between tackle technique and injury reduction for school children remains limited. However, if coach/teacher education is subsequently shown to prevent tackle-related injuries in children, then failure for teachers to be trained would arguably constitute an unacceptable risk. Therefore, regulations for individuals to hold qualifications to teach or officiate tackling in physical education rugby in the United Kingdom would need revision. New Zealand Rugby provide a template to follow here, while the South African Rugby Union have also established an injury prevention programme that all local coaches, at all levels, are required to complete [14]. On the other hand, those without the necessary qualifications could deliver non-contact forms of rugby instead. Unfortunately, however, less than two fifths of teachers who deliver rugby in the United Kingdom have a rugby coaching qualification (which could be historic) [15]. Thus, the New Zealand and South African examples and expertise could - and perhaps should - be leveraged here.

\section{Cautionary Approach}

Given that tackling in rugby arguably meets a number of Molcho and Pickett's criteria for an unacceptable risk for children, we suggest that tackling in rugby is unnecessary and potentially unacceptable in the school physical education curriculum. While we accept that the removal of the tackle may be detrimental to the identity of rugby, the removal of tackling is likely to be the most effective injury prevention strategy in this particular instance [11]. In contexts, such as the community game however, where children and their parents choose (expressed and informed consent) to participate in environments where coaches are expected to hold a rugby specific qualification, we're not calling for the removal of tackling from the youth game.

\section{References}

1. Pollock A M, White A J, Kirkwood G, Evidence in support of the call to ban the tackle and harmful contact in school rugby: a response to World Rugby. Br J Sports Med 2017; 51 (15): 1113-1117.

2. Batten J, White A J, Anderson E, Bullingham R, From management to prevention: the new cure for sports concussion. Br J Sports Med 2016; 50 (21): 1293-1294.

3. Davies, S., Jones, C., McBride, M., \& Calderwood, C. (2016). UK CMO response to: Open Letter: Preventing injuries in children playing school rugby [Online]. http://www.sportcic.com/resources/UK\%20CMOs\%20response\%20to\%20open\%20le tter\%20on\%20preventing\%20injuries\%20in\%20children\%20playing\%20school\%20ru gby.pdf (accessed 18 Nov 2017). 
4. Quarrie, K L., Brooks, J H., Burger, N., Hume, P A., \& Jackson, S. (2017). Facts and values: on the acceptability of risks in children's sport using the example of rugby-a narrative review. Br J Sports Med, 51(15), 1134-1139.

5. Molcho M, Pickett W, Some thoughts about 'acceptable' and 'non-acceptable' childhood injuries. Inj Prev 2011; 17: 147-148.

6. Kirkwood, G., Parekh, N., Ofori-Asenso, R., \& Pollock, A. M. (2015). Concussion in youth rugby union and rugby league: a systematic review. Br J Sports Med, bjsports2014.

7. Wilson L, Stewart W, Dams-O'Connor K, et al. The chronic and evolving neurological consequences of traumatic brain injury. The Lancet Neurology 2017; 16 (10): 813825.

8. Brown JC, Lambert MI, Verhagen E, et al. The incidence of rugby-related catastrophic injuries (including cardiac events) in South Africa from 2008 to 2011: a cohort study. Br Med J Open. 2013:1-10. doi:10.1136/bmjopen-2012-002475.

9. Maclean JGB, Hutchison JD. Serious neck injuries in U19 rugby union players: an audit of admissions to spinal injury units in Great Britain and Ireland. Br J Sports Med. 2011:1-5. doi:10.1136/bjsports-2011-090183.

10. Fuller, C. W. (2007). Managing the risk of injury in sport. Clinical Journal of Sport Medicine, 17(3), 182-187.

11. Cross $M J$, Tucker $R$, Raftery $M$, et al. Tackling concussion in professional rugby union: a case-control study of tackle-based risk factors and recommendations for primary prevention. Br J Sports Med. Published Online First: 11 October2017. doi: 10.1136/bjsports-2017-097912

12. Burger N, Lambert MI, Viljoen W, et al. Tackle technique and tackle-related injuries in high-level South African Rugby Union under-18 players: real-match video analysis. Br J Sports Med. 2016;50:932-938.

13. Hendricks S, O'Connor S, Lambert M, et al. Contact technique and concussions in the South African under-18 Coca-Cola Craven Week Rugby Tournament. Eur J Sport Sci. 2015. doi:10.1080/17461391.2015.1046192.

14. Viljoen W, Patricios J. Boksmart - implementing a National Rugby Safety Programme. Br J Sports Med. 2012;46:692-693.

15. Oxfordshire Rugby Football Schools Union. Training Audit October 2015 [online]. 2015. http://www.oxonrugbyschools.co.uk/governance.php (accessed 25 Feb 2016). 